\title{
Michał Stelmach
}

Warsaw University of Technology

Faculty of Administration and Social Sciences

e-mail: michal.stelmach@pw.edu.pl

ORCID: 0000-0003-3820-1775

\section{HEURISTIC POTENTIAL OF ANTONI KĘPIŃSKI'S INFORMATION METABOLISM MODEL AND DATA SMOG}

\begin{abstract}
In this paper I present the explanatory potential of Antoni Kępiński's model of information metabolism in the question of data smog (data glut, information overload). Kępiński's model is not well known and the bibliography concerning the model of information metabolism is still rather poor. In the article I present the model as a good heuristics for explaining information exchange between the system and the environment. The particular aim of my deliberations is to use the model of information metabolism to discuss the pathological, although common phenomenon of data smog. This allows for a holistic view of the problem and allows for new statements on data smog, ethical consequences and counteracting the negative consequences of information overload.

Keywords: Antoni Kępiński, information metabolism, information, data smog, data glut, information overload.
\end{abstract}

\section{Introduction}

Antoni Kępiński's theory of energy and information metabolism, since it has been formulated until now, has already been accepted, disinterpreted, forgotten, and has recently been re-examined by specialists and is again attracting scientific interest (Ceklarz, 2018). We can speak of a rediscovery, although perhaps not yet a renaissance of Kępiński's thought. My article is part of the stream of rereading the theory of energy-information metabolism and indicating its heuristic attractiveness. Kępiński's bibliography is still not large, the reason is, among other things, earlier attempts to read his thoughts and a large number of misunderstandings (including a purely biological reading of the information metabolism model, or the theoretical status of Kępiński's statements) (Ceklarz, 2018). Kępiński's theory, however, presents itself as an excellent heuristics. In the article I will use Kępiński's 
model to show and explain the action of the phenomenon known as data smog (or data glut, information overload) (Shenk, 1997).

Data smog is a term introduced at a time when the Internet was still only a useful tool, not a "home" or "natural environment" of man. A data smog can be described as an disordered pressure of information, both in quantitative and qualitative terms (Tadeusiewicz, 1999). By analogy to smog as a meteorological phenomenon, it is a destructive phenomenon. The range of its harmfulness extends from personal disorientation, through health effects reflected in populations, to the information war (Snyder, 2018).

I'll start with a terminological remark. In the next part, I will present Kepiński's model of information metabolism. I will point to the central concept of information for the model. I will then move to a brief presentation of the data smog problem. In the next part I will put interpretative hypotheses concerning the heuristic potential of the information metabolism model to explain the data smog phenomenon. In the last part I will summarize the results.

\section{Terminological remark}

The choice of terminology requires a short explanation. Kępiński speaks in some places about energy-informational metabolism and in some places about information metabolism. This is due to the fact that he treats man as a psycho-physical unity, organism, system, (Maciuszek, 2015, pp. 25-29). Energy metabolism is the exchange of energy between the system and the environment (Kępiński, 1972a, p. 231). Information metabolism is an exchange of information with the environment (Kępiński, 1972a, p. 231). In his work, Kępiński focuses on information metabolism and the relations between information metabolism and energy metabolism. For our subject, the model of information metabolism is most important.

The theory of information metabolism was previously considered in purely biological interpretations. The basis for such interpretations were several examples given by Kępiński, illustrating the exchange of information with the environment in analogy to cell behaviour. The biological reading of the theory of information metabolism was criticised (Ceklarz, 2018, p. 171). Jacek Bomba writes:

Kępiński's concept is not a scientific theory. It should not be evaluated according to the criteria typical of such theories. (Bomba, 2001, as cited in Ceklarz, 2018, p. 171). 
It should be noted that scientific criticism of the concept of information metabolism is based on a misunderstanding resulting from biological interpretation. The biological model is not the hard core of the theory, but it is only an example - an image that, by analogy, is supposed to help to properly grasp the meaning of the theory. The issue of the methodological status of the model of information metabolism and its relation to purely biological interpretation was excellently presented by Jan Ceklarz in the article Revision of Antoni Kepiński's concept of information metabolism (Ceklarz, 2018). He postulates the separation of the biological model as an analogous image from the core of the theory, which may prove useful in psychiatry or cognitive sciences as good heuristics. Ceklarz writes:

However, after separating the biological model from information metabolism this anthropological model, which is key in the work of Kępiński, regains its explanatory potential through its simplicity, interdisciplinarity, reliably executed phenomenological description of existential moments of a human, as well as deep rooting in the psychiatry. One of the possibilities to use Kępiński's concept in cognitive science is its reference to the important trends in the works of a neurobiologist Antonio Damasio (Ceklarz, 2018).

Ceklarz sees the possibility of using Kępiński's model in cognitive sciences and referring to Damasio's work. My idea is quite similar. I would like to apply Kępiński's model and show its explanatory potential in interpreting data smog. I cannot discuss Damasio's work here. However, the similarity of the shots lies in the fact that in both cases the same heuristics is used to explain a phenomenon that is of interest to the science.

\section{Kępiński's information metabolism model}

From the biological point of view, Kępiński classifies the signals that come to the system as pleasant and unpleasant. Pleasant ones are responsible for fulfilling the basic needs of the system. Unpleasant indicates a lack of satisfaction, or a risk resulting from this lack (Kępiński, 2014, p. 162). Kępiński points to supreme biological laws generating potentials of fulfilment and non-fulfilment. He calls them: the right to preserve one's own life and the right to preserve the life of the species (Kępiński, 2014, p. 162). The right to preserve one's own life requires fulfillment, and in case of non-fulfillment the system dies. Consequently, it generates a high potential for receiving pleasant and unpleasant signals. The right to preserve the species seems more abstract, because with non-fulfilment of the sys- 


\section{Michat Stelmach}

tem does not die, and the population may die only in extraordinary cases (Kępiński, 2014, p. 162). The basic signals, subjectively perceived as pleasant or unpleasant, give the system roots in the direct contact with the environment. Information metabolism is the exchange of information between the system and the environment (Kępiński, 2012, p. 73). In the case of a primitive system, the metabolism is limited as closely as possible to the realization of biological laws. On the other hand, in humans, pleasant and unpleasant signals refer to a greater spectrum of phenomena than just the realization of the laws of preserving one's own and species' life (Kępiński, 2012, p. 73). In general, Kępiński says that the exchange of energy and information with the environment is the essence of life and distinguishes the world of animated nature from the world of inanimate nature. Life requires an order of information, without it energy metabolism is destroyed and death occurs (Kępiński, 2012, p. 73). The death is a fall into chaos, a deconstruction of order, life is a relative, local order. The order has the potential to be knowledgeable and is an essential component of the life of an intelligent being. Animals that spend most of their lives in isolation suffer from physical (e.g. their cerebral cortex is thinner) and mental (they exhibit a number of pathological behaviors) disorders (Kępiński, 2012, p. 103). Similarly, people undergoing isolation (sensory deprivation), exposed for a long time to monotonous stimuli, or distorted impulses may show a number of mental disorders (Kępiński, 2012, p. 103). They show disorders of simple activities, such as drawing activities. However, the spectrum also includes more serious disorders, such as disorders of logical reasoning, logical thinking in general, or even delusional tendencies (Kępiński, 2012, p. 103).

Information metabolism is found in all animated nature. Kępiński believes that every living organism survives because of the negative entropy of its environment, changing the order of its environment to its own (Kępiński, 2014, p. 164). This applies first and foremost to man, of course, but ultimately it also applies to other species of living beings.

The system is in a constant struggle with the external environment. The fight is to impose an information order. Usually in such a fight the external environment takes an advantage over the individual. The victory of one's own order over the order of the external world is usually combined with pleasant feelings (Kępiński, 2014, p. 169). Kępiński refers to the example of creativity - including artistic creation, i.e., first arranging one's thoughts, building a plan, and then transforming the external environment, organising it according to one's own model. Even in the case of art, the final order is not only the internal order of the system. Moreover, in the artistic creation, when 
it seems that the author is free, the limitations of the author's order come even from the side of the material and the laws that order it. The victory of one's own order over the order of the environment is never complete (Kępinski, 2014, p. 169). The system's own order and the order of the environment co-negotiate the shape of the superior order. The resulting work, whether it is, for example, a work of art, a mountain trip, a philosophical book, or even patches in the garden, or a short cut lawn, is the result of both orders. (Kępiński 2014, p. 169). Each signal coming out of the system has features of the order of the system and the external order (Kepiński 2014, p. 170). However, the power of the system over the environment is usually non-zero. The existing system already changes something important in the order of information in the environment. Usually, apart from the role of "I am ruled" or "participate", there is also the role of "I rule". In nonpathological cases this role is negotiated with the environment. In the case of mental pathologies, however, the role of "I rule" or the role of "I am ruled" takes control over the metabolism. Examples include delusions of power, or delusions of possession (Kępiński, 1972b, p. 94).

The situation of domination of one's own order over the order of the environment is a dream. Paradoxically, during sleep, when the system has the slightest real control over the environment, its informational order is in a distinguished position. However, the order of information in a dream, in the absence of control by the outside world, bears the stamp of disorganization. A high degree of disorganization characterizing sleep is caused by the withdrawal of the system from contact with the environment. The order with a high degree of organization that we find, for example, in knowledge that has a pretension to be objective is a costly achievement and results from adjusting the information order of the system to the information order of the environment. On the contrary, in deep psychoses, autistic tendencies intensify, the information order of the system is withdrawn and deprived of control by the information order of the environment. Thus, the solipsistic or autistic position shows a deforming or even delusional tendency (Kępiński, 2014, p. 168).

In the model of information metabolism, sleep plays a quite important role. Sleep time is a time to organize information. Keppiński claims that the hypothetical role of sleep is to cut off the system from the environment, the reason is that the information coming into consciousness at daylight can be organized. Therefore, information is probably ordered when it is not currently used. Without sleep chaos would arise (Kępiński, 2014, p. 166). Kępiński also explores the hypothesis of the subconscious. Sleep is supposed to order the decisions of the first phase of information metabolism, which are 
probably subconscious, or only partially conscious, and which we perceive subjectively as necessary (Kępiński, 2014, p. 189).

Kępiński introduces the concept of functional structure in his model. A functional structure is a possible behaviour in a concrete situation (definition in behavioural categories). Sometimes Kępiński enriches the notion of functional structure with cerebral and environmental elements, thus extending his definition (Kępiński, 2014, p. 173). Interestingly, in the extended version, Kępiński shows some relativity of functional structures. For example, the functional structure of writing with a pen also includes in the extended version the areas of the brain responsible for writing, the tools, the hand we write. As a result of an accident, areas of the brain may be damaged, but after rehabilitation, their role will be taken over by other areas. Similarly, a person may lose the hand, but the structure will be preserved by changing the writing organ (for example, you can write with your leg, or mouth, or in your thoughts). This notion was apparently developing in Kępiński's work and would probably have been further refined if it had not been for his premature death.

Anabolic processes (processes of formation of functional structures) are partly subconscious (for example, subliminal signals received and sent by the system). Some potential activities are conscious and plannable. Catabolic processes (disintegration of functional structures) also take place in large parts outside the consciousness. The externalisation (realization) of the functional structure causes that it is no longer just a part of the system's conscious life, but functions as an element of the environment and degenerates with time (Kępiński, 2014, p. 173). Functional structures which are not externalized for some time can function in memory. However, most functional structures disappear inside the internal world of one's own system and their reconstruction is most probably impossible (Kępiński, 2014, p. 173).

In the exchange of information with the outside world there is a hidden assumption that the image of the world we perceive is true. Otherwise, the information metabolism would not fulfil its role of preparing for the exchange of energy with the external environment (Kępiński, 2014, p. 178). The exchange of signals with the environment is controlled by a selection mechanism. Only a small part of possible reactions is realized. Similarly, only a small part of the information is made aware and remembered. The selection follows a hierarchy of values. Important values have priority over less important ones (Kępiński, 2014, p. 178).

In the process of selecting the signals, Kępiński sees positive feedback. The positive feedback hypothesis recognizes that the predominance of positive emotional states results in the search (selection) of positive signals. 
Therefore, the "optimist" will select pleasant signals and will look for them. The prevalence of negative emotional states causes the selection of negative signals. A person in depression will only find negative features of the environment. The psychiatrist deals with pathologically fixed functional structures (Kępiński, 2014, p. 179). Their dynamics is different depending on the type of pathology. In depression the dynamics of functional structures is rather small, as opposed to the great growth in acute schizophrenia (Kępiński, 2014, p. 179).

Kępiński distinguishes two phases of information metabolism. The first phase is characterized by taking a fundamental "from" or "to" attitude (fight or escape, love or hatred, interest or dislike). The emotional colouring is the subjective equivalent of satisfying or not satisfying the basic needs of the system and it prepares the system for further interaction with the environment (Kępiński, 2014, pp. 187-188). Reactions of the first phase of information metabolism are subjectively perceived as necessary, they are not easy to modify and replace, so it is difficult and expensive to change typical emotional attitudes to elements of the environment. We have no influence on the vegetative-endocrine reaction. We can only manage the basic attitude to a small extent (Kępiński, 2014, p. 188). Reactions of the first phase of information metabolism are relatively primitive and generaly reduced to pleasure and sorrow (Kępiński, 2014, p. 188).

The second phase of information metabolism creates and selects more complex models of reactions to the external environment. The functional structures adapt to the situation. The most frequently repeated structures have the greatest potential for fulfilment. Of the various possible reactions, one is selected. The choice of a healthy person will be more or less adequate, within the limits of errors resulting from possible erroneous actions. Reactions of a person with mental pathologies may not be adapted to external circumstances. However, the choice is not entirely transparent as it is linked to the first phase of information metabolism. Therefore, the type of reaction to the environment (type of selected functional structure) may be different in a friendly and joyful attitude, on the one hand, or anxious and aggressive on the other (Kępiński, 2014, p. 189). The functional structures are partly consciously produced, it is possible to plan activities. Of course, having control is not necessary in the second phase of information metabolism, as the following example will show. The telephone is ringing in the room. Usually a ringing signal disturbs us a little from our previous activities (there is an element of surprise in this). The bell usually causes us a slight shock (first phase). A typical reaction for the second phase is to answer the phone and say "hello". This is also the most probable reaction. But Kępiński, who had 


\section{Michat Stelmach}

to deal with psychiatric patients, shows that this is not the only reaction. After all, it is possible to break the phone, drop it and leave the house, throw the phone out the window, go crazy and start screaming (second phase). In this example we can see how much depends on the type of reaction of the first phase, that is, on the feeling or emotional attitude to the situation (Kępiński, 2014, pp. 187-188). This choice belonging to the first phase determines what kind of functional structures can be created by the second phase of information metabolism (Kępiński, 2014, p. 200). This variety of functional structures makes Kępiński conclude that it is impossible to completely predict human behaviour (Kępiński, 2014, p. 190).

\section{The concept of information in the Kępiński model}

In this part I would like to present the concept of information used in the theory of information metabolism. I will summarize and generalize the previous definitions of information from the previous part of the paper.

Information creates an image of the world and organizes models of reality (Kępiński, 1972a, p. 231; Kępiński, 2014, pp. 223-227). Primitive organisms react to the environment as pleasant or unpleasant, friendly, or unfriendly. In the case of humans, we are already talking about something more than just an image of the world, which boils down to the perception of pleasure and sorrow, resulting in a fight or escape. The first phase of information metabolism is responsible for this. The second phase enriches the image of the world with additional interpretations (planning, projection into the future, interpretation and reinterpretation of the past, conscious decisions about the current situation, etc.). The image of the world is a holistic interpretation of information flowing into the system including past, present and anticipation of the future (given in plans projected into reality). Thus, the image of the world is new information that organizes the previous information. The world image is important for the positive feedback effect, it plays a role in strengthening the selection of pleasant (optimist) or unpleasant (pessimist) signals. The world's images aim at local consistency (rationalisation) and, in the case of scientists, for example, at maximising consistency and adequacy. Reality models are current behavioural plans resulting from a two-phase interpretation of information flowing into the system from the environment (Kępiński, 2014, p. 189). On the one hand, they include past information (e.g. image of the world, memory data, subconsciousness, etc.), on the other hand, current information reaching the system from the environment. It seems, however, that Kępiński also takes 
into account information coming from inside the system (e.g. if my stomach hurts, I can project into the future a model of the world in which I do not take a planned bicycle ride). Similarly, world models can take into account information about the predicted shape of the future (e.g. if I know the weather forecast, I can postulate a world model that does not take into account a bicycle ride). The world picture influences the models of reality (e.g. if the world picture is dominated by a catastrophic perception of reality, information about dangers is selected, the current model of reality may exclude the plan of the ride - as e.g. too dangerous activity).

The information organizes, but also the information is organized. Due to the multilateral nature of the notion of information, the ordering will take place in different ways. Information organizes a certain sphere of reality. But in the case of researching a particular person, a single information is an analytical, abstracted concept, in reality there are rather streams of information and their dynamic flow. Information is subject to selection and only a small part of information from the environment reaches consciousness. Information is open to hierarchisation. More important signals are selected, according to the current hierarchy of values (Kępiński, 2014, p. 178).

In the selection of information not only the conscious interpretation of data takes part, but also unconsciousness, memory data, the image of the world supporting positive feedback, moods, feelings, etc. In connection with two phases of information metabolism, I propose a nomenclature which, in my opinion, reflects Kępiński's intentions. I propose that the information of the first phase of informational metabolism (attitude "from", or attitude "to"; 1 , or 0; pleasant, or unpleasant; positive, or negative; love, or hatred; tendency to fight, or escape) to be called meta-information. They play a very important role, as they design the further development of models of reality. Their subjective modal correlate is necessity in the Greek sense of ananke (Kępiński, 2014, p. 189). Meta-information is the first emotional attitude towards other information reaching the system. Thus, it organizes models of reality in such a way that, in the first reflex, it allows to realization, it supports the aspiration to realization, or, on the contrary, it orders a distance, an escape from some supposed possibilities. In longer time one can change the emotional attitude of the first phase of information metabolism. Thus, the first phase (meta-information) is not static in the sense of unchangeability, but it is actually unmodifiable and is not subject to the current orders that run according to certain preferences resulting from the image of the world. For example, in the current model of reality, a high altitude may cause current fear (first phase, meta-information). But I can start to see myself as a coward and be ashamed of my fear (meta-information 


\section{Michat Stelmach}

in the new model) when I reflect (building a new, or at least reinterpreted model of reality). A properly managed second phase (e.g. training plan and implementation of individual altitude training stages) can change the typical reaction to the first phase (e.g. high altitude). The anxiety component in climbing is rather a constant (and necessary) element, but it will lose its dominant role to meta-information (trained in longer time and positive attitude "to", confrontation with anxiety). Generally, meta-information is an information, but it currently plays a special role in the development of contact between the system and its environment. This role may change. Then we talk about information as a typical reaction to a certain type of phenomenon (not just a mental fact), but rather a meta-information as a type. In the model of information metabolism we have to distinguish information as concreteness and information as type.

The information of the second phase is simply called "information", without the prefix "meta". They play the role of organizing the system's contacts with the environment, are subject to planning and development, interpretation and reinterpretation. As such, they are material for memory. They can be consciously elaborated. The order occurring in the second phase generates many possibilities. While meta-information is poor, although this does not mean that it is uninteresting. Information of the second phase is potentially infinite because, it overlaps with the diversity of the environment, body, external and internal world, relations between their elements, etc. Their diversity is overwhelming. The information can be used adequately, or inadequately, to model the system's contact with the environment. The order of information selected by the system influences the order of the environment (man operates on information). But also the order of the environment has an impact on the order of the information that reaches the system (the norm for exchanging signals with the environment is maximum adequacy). The order of information resulting from contact with reality is a characteristic feature of every system. Consequently, relations between the orders are complicated. The external order is not always an external world order. In contacts with the world and people it must be remembered that every person negotiates his or her order with the environment (as the world), as well as with the environment (as other people). So the information metabolism is generally speaking an exchange of information with the environment, but a part of this environment (e.g. people) additionally exchanges information with its environment (of which other people are part). Further implications are typical features of information metabolism of e.g. different genders, nations, cultures, personality types, occupational groups, etc. (Mitarski, 2014, pp. 268-309). 
The information in Kępiński's model needs a subject of perception. Therefore, Kępiński's concept is different from the concept of information without subject, such as Norbert Wiener's environmental information (Tworak, 2018, pp. 30-32). Wiener includes information as a feature of the environment, which is independent of the perception. In the model of information metabolism, the tautological statement is that the exchange of information takes place in relation to the environment. The subject is a living organism, not necessarily a conscious subject (in the sense of man). Man is one of many subjects of metabolic information exchange with the environment.

\section{Data Smog - short presentation}

Data smog is a term introduced in 1997 by David Shenk (Shenk, 1997). Shenk found that we live in a world of information overload. Information reaches us in a gigantic, unprecedented number and intensity. In the past, information was hard to get. Today information is common and has lost its value. The computer has become available in every home, and consequently, knowledge, but also potential sources of danger have grown. In today's world it is difficult to maintain the necessary level of criticism of knowledge coming from authority. One could even say that everything seems to suggest that there are too many experts, and this does not help the clarity of our view (Shenk, 1997). Behind the excess of information there is a market and financial impacts on a large scale. Information available in the Internet era often comes in a diluted and imprecise form. In the era of data smog, stories are radically simplified. The truth turns into opinion. Everyone can promote their own (Shenk, 1997).

Smog is originally a meteorological phenomenon (Tadeusiewicz, 1999, pp. 99-100). In analogy to meteorological smog, data smog is disorderly, heterogeneous and information overload (Rachfall, Williamson, Temple, 2014, p. 28). In the era of advanced technologies, information reaches its recipients faster. This can have both good and bad effects. When there is too much information, then the mechanisms of criticism and data processing stop working efficiently (Roetzel, 2017, p. 480). Information overload makes it impossible to understand messages and also makes decisions impossible (Hemp, 2009). Lack of criticism in getting and evaluating information could lead to the acceptance of unverified data. These may turn out to be false, then - from the point of view of information theory - the final entropy of the system is growing (Tadeusiewicz, 1999, p. 100). Moreover, the voice of 
a fool is as audible as the voice of a true authority, so in the absence of criticism it may seem attractive (Tadeusiewicz, 1999, p. 104). In the mind of the recipient, there is a large number of unexamined, raw information. This causes confusion in knowledge and may lead to total disintegration in the field of values (Tadeusiewicz, 1999, p. 104).

Information technologies are developing, but the phenomenon of information overload is not weakening, it is strengthened by, for example, social media, commercials, videos, online films, television (Tadeusiewicz, 1999, pp. 102-103; Iarvie, Pralong, 2003, p. 36; Popper, 2012, p. 417). We can see the negative impact of information overload in the fields of business, economics, knowledge, education, but also health. In response to the need to organize one's own life, there are recommendations for ethical rules, commandments or rules of good conduct in the use of advanced information technology (Hartney, 2019).

\section{The heuristic potential of the information metabolism model and the explanation of the data smog phenomenon}

In the present part of the article I will describe the phenomenon of data smog according to Kępiński's heuristic model of information metabolism, and then I will describe the similarities of basic concepts. Kępiński's model shows information as ordering and ordered. The information is arranged hierarchically in order of higher levels. The order introduced by metainformation of the first phase of information metabolism is simple and at the same time generates further developments. The second phase introduces more complex orders and is established within the system's contact with the environment. The pathological situation is cut off from stimuli coming from the external environment on the one hand and information overload on the other. In the absence of stimuli, the metabolism shows some pathological features resulting from the inability to confront the produced functional structures with the external world. The image of the world is formed during the contact of the system with the external environment. If the external environment does not provide stimuli, then solipsistic tendencies gain an advantage. The own order wins, but the effect is a world, without the feature of reality, a dangerous world, because it is fictional, imagined, untrue.

The same is true for information overload. The phenomenon takes on the opposite direction. The world is pressing. However, too many stimuli affect the phase order of information metabolism. The second phase of metabolism 
influences the first phase, the evaluations are verified and modified in larger time scales. However, if the information is too dense, the second phase of informational metabolism affects the first phase in empirically smaller time scales. The first phase provides a negative signal. The consequence is some form of suffering, such as a feeling of exhaustion, desire to withdraw, aggression, escape, or attack. Chaos created as a result of overload displaces the order of the system (the order of information collected so far and ordered in normal circumstances). The increase of information is in normal circumstances an increase of order. However, this phenomenon has its limit - the ability of assimilation of the subject. These abilities can be modified and trained. Modern man lives in an environment contaminated with an excess of information and therefore he also shows some local adaptations (thanks to which he can still live in this environment without going mad). Information overload causes an increase of stress (Kępiński uses the term stress). Stress causes complications, and ultimately chaos in the further course of cognitive activities. Chaos causes chaos, and this amplifies the general entropy of information metabolism. The general narration of Kępiński's theory corresponds to the data smog theory. Kępiński's theory allows for structural ordering of sources and activities of data smog. I will now move on to the characterisation of concepts and the similarities.

Information metabolism. Information metabolism is treated as an exchange of information with the environment. The exchange is a flow from the environment to the subject, as well as from the subject to the environment (where other recipients may exist). In the data smog theory we also assume that the subject is capable to receive information. Although the environment may include other beings than man that receive information, also machines, the concept of data smog is characteristic to the human of the technical civilisation. Kępiński's theory talks also about players who are not human and who are able to exchange information. Although Kępiński does not pay special attention to animals, for example, but the theory of information metabolism is supposed to apply to the whole world of animated nature (including plants at some primitive level). The exchange can of course be stimulated and controlled by the mechanisms of the second phase of information metabolism. Therefore, it is possible for an intelligent entity to decide to increase the information emission as well as to limit it. However, it is good to look at some ideal boundaries. To a certain extent, the interference in the information environment is controllable. Of course, the presence of an entity in the environment is not neutral from the point of view of information exchange and is information itself. But between silence and increased level of information emission there is a spectrum of possible 


\section{Michat Stelmach}

forms. Therefore, in the face of the phenomenon of information overload it is possible to adopt an attitude of carefulness and criticism, which is suggested by some ethical ideas accompanying the debate about the data smog. On the contrary, it is possible to flood the environment with information in a deliberate and calculating way (e.g. information warfare), in the final form leading to chaos.

Fighting for order. Kępiński claims that the system is fighting for its own order. We already understand that this own order is produced in contact with the environment, which means that it has co-authors. In the phenomenon of data smog we can find a similar relation. Information does not necessarily have to be sent by foreign intelligence services or wicked politicians. In fact, it is possible to imagine a situation in which subjects in good faith litter the environment with information, each of which seems useful, helpful, maybe even true to certain subjects. The Internet is a place where you don't necessarily have to be wicked to leave behind unnecessary information. The phenomenon of data smog starts to work when that is a lot of such information is gathered.

The dream and its role. According to Kępiński, sleep and rest play a certain role in organizing information. Information overload causes stress, which negatively affects sleep. A person subjected to an overload of information assimilates information in a disturbed way. The phenomenon generates a vicious circle - information chaos causes worse absorption of information, worse absorption of information causes chaos. Such a phenomenon has a big neurotic potential (Kępiński, 1986, pp. 175-177). Hence the diagnoses characteristic of our times, made by psychiatrists for a long time (Horney, 1994).

Internal order - external order. The modal division into internal and external order can also be found in the data smog phenomenon. This is precisely the point that internal order requires contact with external order. Otherwise it disintegrates. The external order is interpreted in two phases of informational metabolism and finally integrated (in a normal situation) or rejected (e.g. in psychosis). In case of excessive complication and chaos of the external order, the system may react differently. Typical reactions will include escape, inversion of evaluation (e.g. what cannot be understood is not worth knowing), aggression, anxiety, disorientation, or positive reactions such as critical thinking, data selection, searching for reliable sources. Withdrawal from interactions with the environment is covered by a high degree of disintegration (Kępiński, 2014, p. 168). Critical thinking and selection of good information is time-consuming. Cognitive processes become more costly. 
Anabolic and catabolic processes. The production of functional structures may be impaired by both lack of and excess information. Boundaries are relativised to some extent subjectively, but generally quite typical for the species. In Kępiński's model, the formation of potential functional structures involves the subconscious, which is not directly manipulated, although it can be influenced to some extent. But Kępiński also talks about the potential role of sleep, which can be disturbed by an excess of information. However, more important than the psychoanalytical aspects of Kępinski's view is the social aspect of the formation of functional structures. Man as an individual does not invent the world, but reacts to it and interprets it creatively. In this aspect, Kępiński's theory shows that the information metabolism of a child, as especially exposed to influence, faces a great danger. Moreover, that acquiring information does not have to be understood as thinking, developing, synthesizing, organizing, and can be chaotic and destructive (Taylor, 2012).

Kępiński understands catabolic processes as making the functional structure "not mine". He distinguishes two possible ways. The first one, the structure realized, is no longer a part of me, but of the world. The second, a forgotten structure, or one that cannot be remembered. The data smog includes both ways. For example, the data smog makes things difficult to remember. Costly information selection processes make it less memorable (Murayama et al., 2016). Memory modified by the influence of data smog is overloaded. We have less of potential action structures that are forgotten and not remembered.

Assumption of truthfulness and positive feedback. The information obtained through normal exchange with the environment is perceived as true. Kępiński's model shows that we assume the truthfulness of data from the outside world. When certain functional structures have been routinely implemented, the probability of implementing similar structures increases. In a normal situation we respond to data of a certain type by implementing the most probable, adapted structures. Of course, in psychoses, the situation is pathologically disturbed. Positive feedback consists in the selection of information that matches the previous system of collected information. In connection with the overload of information, there is a danger of selecting and strengthening information from poor sources (for example, from immoral regimes, bad politicians, influential but despicable journalists, or uncritically from social media). Many researchers draw attention to the ethical aspect of the phenomenon (Tadeusiewicz, 1999, pp. 103-104; Himma, 2007, p. 259; Doomen, 2009, pp. 27-36). The phenomenon is dangerous, because delusional tendencies resulting from a ap- 
parently coherent system of false information, and which are stronger in subsequent stages of selection, may be used, for example, in the information war (Snyder, 2018).

Two phases of the information metabolism model. The first phase in normal communication is spontaneous and intuitive. The second phase develops richer structures and secondly influences the evaluation of the first phase (for example, a dish that looks appetizing may harm us, then with subsequent contacts it will probably stop looking appetizing and start evoking unpleasant memories). In phase one the overload of information is perceived as chaos, mess, and thus as a negative phenomenon. In the second phase information of a more complicated structure is obtained. While the first phase is spontaneous and needs little time for evaluation (we perceive it subjectively as immediate), the second phase requires more time, it is discursive and is mediated by interpretation. The multitude of information pushes the viewer to constantly redo the first phase. Instead of organizing the data assimilated in the first phase, we go back to the emotional reactions of the first phase. The risk of such a phase shift is big, because knowledge is not only a well-established emotional reaction to some type of data. Moreover, going back to the first phase of information metabolism, renewing the emotional response, or a strong emotional response disrupts learning processes and slows down learning (Pawar et al., 2018).

Predicting new phenomena. Kępiński's model of information metabolism allows for predicting new phenomena. Apart from its explanatory potential, it also contains the potential to derive predictions from new data. The model of information metabolism allows to predict that in situations of information chaos, information warfare, there will be a strengthening of delusional tendencies among recipients of information. The overload of information metabolism may lead to a number of consequences, which range from personal life complications of an individual person to phenomena in the field of societies, nations, states. The global consequences of the overload of information, which are predicted by Kępiński's model, may include such dangerous phenomena as destabilisation of states, increase of aggression, increase of the feeling of threat among entire communities. Kępiński's model allows predicting the dangers resulting from the information war, but it also works well for studying and predicting the phenomena accompanying more everyday aspects of information overload. 


\section{Summary of the results}

Kępiński's model of information metabolism can be successfully used as a good and promising heuristics in research on the phenomenon of data smog. Information overload is an important phenomenon, because it concerns contemporary man practically as a whole species and is researched by many sciences, such as information science, psychology, psychiatry, biology, sociology, economics, philosophy. Kępiński's model describes the problem well and shows heuristic potential. Kępiński's model allows us to predict many phenomena, such as confusion in the sphere of moral values resulting from information chaos, breakdown of authority, success of information wars, stealing information, control of information streams, emotional overload and economic inefficiency of employees. The first part of the text successfully describes Kępiński's model, which is rather unknown to the English-speaking reader. The next result is a presentation of Kępiński's model and a description in the language of the model of the basic features characterizing the data smog. Kępiński's model allows for a coherent description of the phenomenon and drawing further conclusions from it, including ethical aspects of information.

The Kępiński's model presents the phenomenon of information overload as a disturbance in coordinating the order of information through a twophase information metabolism system. Chaos is caused by excess and disorderly information. Both factors support each other and together cause negative changes in system functioning. As empirical studies show, the effect of data smog can be suffering, stress, loss of subject's efficiency, loss of knowledge, economic losses, damage to health, including mental health, decrease of criticism threatening manipulation with unlimited potential development. Kępiński's model describes the exchange of information in terms of fighting and negotiating order. In the situation of lack of order and overload, pathology occurs. Kępiński's model predicts the sleep disturbances caused by the information overload shown in empirical studies. The model shows that the lack of sleep will generate secondary stress, which in turn makes sleep more difficult. Then the efficiency of the knowledge acquisition system decreases. The model predicts disturbances in the relation between the internal and external order. This allows to explain the success of false statements promoted by dishonest authors, for example in social media. Disturbances in anabolic and catabolic processes predicted by Kępiński's model are consistent with empirical research on the overload of memory and the influence of information overload on the learning process. Kępiński's model also shows the mechanism by which the data smog can be used as a weapon 
in an information war. There is a danger of strengthening delusional tendencies accompanying a apparently coherent system of false information and its uncritical selection. Kępiński generally says that giving up reason and critical thinking is always a negative phenomenon. The Sleep of Reason Produces Demons (Wiercioch, Szymska-Wiercioch, 2019).

\section{R E F E R E N C E S}

Ceklarz, J. (2018). Revision of Antoni Kępiński's Concept of Information Metabolism. Psychiatria Polska, 52(1), 165-173. https://doi.org/10.12740/pp/65751

Doomen, J. (2009). Information Inflation. Journal of Information Ethics, 18(2), 27-36. https://doi.org/10.3172/jie.18.2.27

Hartney, E. (2019). Ten Basic Rules of Netiquette or Internet Etiquette. Know Your Manners When Using Technology. Retrieved May 31, 2020 from: https://www.verywellmind.com/ten-rules-of-netiquette-22285

Hemp, P. (2009). Death by Information Overload. Harvard Business Review, 2009(09). Retrieved May 31, 2020 from: https://hbr.org/2009/09/death-byinformation-overload

Himma, K. E. (2007). The concept of information overload: A preliminary step in understanding the nature of a harmful information-related conditio. Ethics and Information Technology, 9(4), 259-272. https://doi.org/10.1007/s10676007-9140-8

Horney, K. (1994). Neurotic Personality of Our Time. New York: Norton.

Iarvie, I., Pralong, S. (2003). Popper Open Society After 50 Years. The Continuing Relevance of Karl Popper. London, New York: Routledge.

Kępiński, A. (1972 a). Rytm życia (Rhythm of life). Kraków: Wydawnictwo Literackie.

Kępiński, A. (1972 b). Schizofrenia (Schizophrenia). Warszawa: Państwowy Zakład Wydawnictw Lekarskich.

Kępiński, A. (2012). Lęk (Anxiety). Kraków: Wydawnictwo Literackie.

Kępiński, A. (2014). Melancholia (Melancholy). Kraków: Wydawnictwo Literackie.

Maciuszek, J. (2015). Obraz człowieka w dziele Kępinskiego (The Picture of Man in Kępinski's Work). Toruń: Wydawnictwo Naukowe im. Mikołaja Kopernika.

Mitarski, J. (2014). Z dziejów melancholii (From the history of melancholy). In A. Kępiński, Melancholia (Melancholy) (pp. 268-309). Kraków: Wydawnictwo Literackie.

Murayama, K., Blake, A., Castel, A., Kerr, T. (2016). When Enough Is Not Enough: Information Overload and Metacognitive Decisions to Stop Studying Information. The Journal of Experimental Psychology: Learning, Memory, and Cognition, 42(6), 914-924. https://doi.org/10.1037/xlm0000213 
Pawar, S., Jacques, T., Deshpande, K., Pusapati, R., Meguerdichian, M. J. (2018). Evaluation of cognitive load and emotional states during multidisciplinary critical care simulation sessions. BMJ Simulation and Technology Enhanced Learning, 2018(4), 87-91. https://doi.org/10.1136/bmjstel-2017-000225

Popper, K. R. (2012). After The Open Society. Selected Social and Political Writings. London, New York: Routledge.

Rachfall, T., Williamson, E., Temple, B. (2014). The information overload phenomenon: the influence of bad - and (ir)relevant information. The International Journal of Research in Engineering and Technology, 03(17), 27-32. https://doi.org/10.15623/ijret.2014.0329005

Roetzel, P. G. (2017). Information overload in the information age: a review of the literature from business administration, business psychology, and related disciplines with a bibliometric approach and framework development. Business Research, 2019(12), 479-522. https://doi.org/10.1007/s40685-018-0069-z

Shenk, D. (1997). Data Smog. Surviving the Information Glut. Chicago: Harper Collins E-BOOKS.

Snyder, T. (2018). The Road to Unfreedom. New York: Tim Duggan Books.

Tadeusiewicz, R. (1999). Smog informacyjny (Data smog). Work of the Committee on Civilisation Threats. Kraków: Polska Akademia Umiejętności.

Taylor, J. (2012). Are Your Children Overloaded with Information? Children these days are drowning in a sea of media-supplied information. Retrieved May 31, 2020 from: https://www.psychologytoday.com/us/blog/the-powerprime/201212/are-your-children-overloaded-information

Tworak, Z. (2018). Informacja, wiedza, logika (Information, Knowledge, Logic). Poznań: Wydawnictwo Naukowe Uniwersytetu Adama Mickiewicza.

Wiercioch, W., Szymska-Wiercioch, J. (2019). Psychiatra i demony. Powieść biograficzna o profesorze Antonim Kepinskim (A psychiatrist and demons. A biographical novel about Professor Antoni Kęiński). Warszawa: Wydawnictwo MG. 